\title{
Analysis of the post-earnings announcement drift anomaly on the JSE
}

\begin{abstract}
The post-earnings announcement drift anomaly has been widely researched and confirmed for several markets around the world. This paper investigates the relationship between the earnings surprise as reflected by the price change immediately after the earnings announcement and the subsequent price drift over the next 120 days, called the PEAD effect. Evidence obtained for JSE listed shares over the period from 1991 to 2010 indicates that the PEAD effect is present, that its magnitude is statistically significant and that it exists independently of the size, value and momentum effects. The results indicate that after the initial reaction to the announcement, it is not until about the $20^{\text {th }}$ to $40^{\text {th }}$ trading day after the announcement that the share price starts drifting in the same direction as the initial reaction. Contrary to previous research that confirmed the overreaction phenomenon on the JSE for the period 1975-1989 (Bhana, 1995), the market therefore seems not to over- or under-react to the earnings information, but to receive confirmation in the two months following the announcement that is in line with the announcement - in the case of a positive surprise this confirmation may be indicative of better future prospects and that the higher than expected earnings might persist.
\end{abstract}

\section{INTRODUCTION}

The efficient market hypothesis (EMH) (Bodie, Kane, \& Marcus, 2005) is a cornerstone of modern finance theory and is based on the premise that all market participants form rational expectations about future security returns. Therefore a security's price at any point in time is the aggregate expected value of the present value distribution calculated from all future estimated cash flows (Bodie et al., 2005). In other words, a security's (asset) price already contains the market's expectation of future cash flows and growth. The EMH has come under scrutiny and a great deal of research effort has gone into identifying and analysing anomalies to this hypothesis. Although some of the anomalies that have been observed can be explained by some form of risk premium, others claim to contradict the $\mathrm{EMH}$ and questions its validity.

A specific anomaly to the efficient market, called the overreaction hypothesis, has been observed by $\mathrm{De}$ Bondt and Thaler (1985). Their research indicates that the stock market tends to overreact to unexpected news events such as earnings announcements that exceed expectations. They further show that equities that experience the highest (lowest) return in response to an event tend to underperform (overperform) in the subsequent period, therefore 'correcting' its mistake. They hypothesise that the reason for the overreaction is the market's inefficient response to the earnings information. Similar behaviour was observed by Brooks \& Buckmaster (1980) who noted that earnings deviate from a random walk after experiencing extremes and tend to revert back to their long-term mean.

* School of Electrical and Electronic Engineering, North-West University, Potchefstroom, Republic of South Africa.

Email: swart.niel@gmail.com; alwyn.hoffman@nwu.ac.za
An anomaly opposite to the overreaction hypothesis, namely the under-reaction anomaly, has also been found to exist. This anomaly is explained as the slow reaction of market participants to new information such as earnings announcements, which constitute an initial under-reaction which is gradually corrected as cumulative share returns tend to drift in the same direction of the initial earnings response for a substantial period after the announcement has been made (Ball \& Brown, 1968; Choi \& Kim, 2001; Hong \& Stein, 1999; Foster, Olsen, \& Shevlin, 1984). Thus the cumulative share returns of companies which announce higher (lower) than expected earnings tend to drift upwards (downwards) for a period after the information has been made public. The under-reaction phenomenon is more commonly known as the postearnings announcement drift (PEAD) anomaly.

A fundamental principle of efficient markets is that any new information ought to be reflected in share prices almost instantaneously and the adjustments should be fair according to the new information received. Predictable patterns such as market overreactions and under-reactions and their respective subsequent corrections should not exist in a perfectly efficient market.

The primary purpose of this paper is to establish whether the PEAD anomaly occurred on the Johannesburg Stock Exchange (JSE) for the period 1991 to 2010. A secondary purpose is to determine whether any relationship exist between the PEAD effect and a list of known market anomalies, including the size effect and the value effect. The statistical significance of the PEAD effect will be investigated; establishing its economic significance by calculating excess risk-adjusted returns and taking into account real-world trading constraints is however beyond the scope of this paper. 
The remainder of this research is outlined as follows: Section 2 gives an overview of previous research relevant to this study of the post-earnings announcement drift anomaly and of related local research done on the Johannesburg Stock Exchange (JSE). Section 3 discusses the data and methodology used to conduct the research and Section 4 presents and discusses the results obtained. Section 5 concludes the paper with a summary of the findings.

\section{PREVIOUS RESEARCH}

Ball and Brown (1968) were the first to discover that for a significant period after earnings announcements, cumulative returns continue to drift upwards for positive unexpected earnings announcements or "good news" and downwards for negative unexpected earnings announcements or "bad news". This phenomenon, known as the post-earnings announcement drift anomaly, has been widely researched since.

Foster et al. (1984) found that variables coding the sign and magnitude of the earnings forecast error and firm size independently explain $81 \%$ and $61 \%$ respectively of the variation in post-announcement drifts with a joint explanatory power of $85 \%$. They also found that systematic post-announcement drifts in security returns are observed only for a subset of the earnings expectations models examined. Of the four expectations models they used in their research, they found post-announcement drifts for the two expectations models that are based on the past quarterly earnings series. However, for the two expectations models based on the security return series, post announcement drifts are not observed. Their research highlights not only the significance of the post-earnings announcement drift but also its relationship with firm size. This will also be investigated for the JSE in this paper.

Chordia, Sadka, Goyal, Sadka, \& Shivakumar (2007) found that the post-earnings-announcement drift mainly occurs in highly illiquid stocks. A trading strategy that goes long the high earnings surprise stocks and short the low earnings surprise stocks earns a return of only $0,24 \%$ per month in the most liquid stocks but $1,79 \%$ per month in the most illiquid stocks. The illiquid stocks however have high trading and market impact costs; Chordia et al. (2007) estimated that transaction costs account for anywhere from $66 \%$ to $100 \%$ of the paper profits from the longshort strategy they designed to exploit the PEAD anomaly. This again highlights the relationship of the reaction to earnings surprises with liquidity which in turn is highly correlated with firm size.

Kaestner (2006) has shown that the two kinds of anomalies, namely under-reaction and overreaction, are inextricably linked. While under-reaction defines a delayed reaction of security prices to new information, overreaction is the extreme reactions of security prices to previous information or past performance. The PEAD anomaly is therefore an example of the underreaction anomaly. Theoretical Behavioural Finance models have shown that both under- and overreaction can potentially be explained by investor irrationality. Kaestner (2006) investigates current and past earnings surprises and the market's subsequent reaction over the period 1983-1999 for listed US equities. The results suggest that investors simultaneously exhibit short-term under-reaction to earnings surprises and long-term overreaction to past highly unexpected earnings (momentum behaviour). The work of Kaestner therefore illuminates the relationship between earnings surprises and another documented anomaly, namely momentum behaviour. The relationship between momentum and the postearnings announcement drift as observed on the JSE will be further investigated in this research.

Published local research regarding the reaction to earnings announcements and the PEAD anomaly on the Johannesburg Stock Exchange (JSE) is limited. Previous local studies that investigated the market's reaction to announcements include, amongst others, the investigation of the reaction of the market to the announcement of share dividends (Bhana, 1997), special dividends (Bhana, 1998), the announcement of management buyouts (Bhana, 2005) and share repurchase announcements (Bhana, 2007).

Notable local research on the market's reaction to earnings announcements was however done by Bhana (1995) in his investigation of the overreaction hypothesis on the JSE. Bhana's research provides evidence that for the period under investigation (1975 to 1989) the market overreacted to unexpected earnings announcements. This behaviour was found not to be symmetrical: firms with lower than previous earnings (negative change) performed better than the market in the subsequent period, thus constituting an initial negative overreaction to the lower expected earnings that is subsequently corrected; however, firms with a positive change in earnings and a corresponding initial positive reaction did not subsequently perform significantly worse than the market.

Bhana's analysis of the abnormal share returns accumulated over twelve-month periods following annual earnings announcements reveals that a strategy of buying shares of companies that announced a negative change in earnings, and holding these shares for the next twelve months, would generate positive risk-adjusted abnormal returns of about $12,5 \%$ before transactions costs. The observed negative earnings effect exists independently of any small-firm effect. It was also found that companies reporting negative earnings in any test year experienced, on average, strong earnings recovery over the next two years. 
A large body of research on the PEAD effect has provided possible explanations for the phenomenon. Although this paper does not try to establish the validity of these proposed explanations, a review of some of them and their relationships with the PEAD effect is deemed in order. Lundstrum (2010) reviews many of the conflicting views regarding the explanation of post-earnings announcement drift over the years. Among the numerous explanations for post-earnings announcement drift cited in Lundstrum (2010) and other sources are investor under-reaction or delayed price response (Bernard \& Thomas, 1989; Hou \& Moskowitz, 2005; Marais, 1989), not fully taking inflation into account (Chordia \& Shivakumar, 2005), information uncertainty (Francis, Lafond, Olsson, \& Schipper, 2007), arbitrage risk (Mendenhall, 2004; Shleifer \& Vishny, 1997), firm size (Foster et al., 1984) and liquidity risk (Chordia et al., 2007; Sadka, 2006), an earnings surprise risk factor (Kim \& Kim, 2003), transaction costs ( $\mathrm{Ng}$, Rusticus, \& Verdi, 2008), trading volume (Choi \& Kim, 2001) and trader behaviour (Shanthikumar, 2004), (Kaniel, Shuming, Saar, \& Titman, 2008). According to Lundstrum the most likely explanations for the post-earnings announcement drift anomaly include the limited arbitrage hypothesis and the illiquidity hypothesis. The limited arbitrage hypothesis as proposed by Mendenhall (2004) and Shleifer and Vishny (1997) claims that arbitrageurs are deterred from exploiting excess returns associated with PEAD because they are concerned about the associated idiosyncratic risk involved. Lundstrum presents new evidence that illiquidity, rather than limited arbitrage explains the post-earnings announcement drift.

In this research we limit our investigation firstly to establishing the existence of the post-earnings announcement drift anomaly on the JSE and secondly investigating the relationship of post-earnings announcement returns with a number of well-known anomaly variables, namely momentum, the value effect as well as firm size and liquidity.

\section{DATA AND METHODOLOGY}

\subsection{Data}

JSE share data was sourced from McGregor BFA for the period from the start of 1991 to the end of 2010. All earnings announcement data of which the announcement date is known over the 20 years are used. This represents a sample of 4838 observations including 284 different companies, which consists mainly of dividend paying stocks, because the announcement dates for the stocks that declare no dividends are not available on McGregor BFA's website. This limitation is clearly stated to ensure the correct interpretation of our results. We can however pose the argument that this will not detract from the validity and usefulness of our findings, as an investor always has the option to limit his investments to shares that comply with specific criteria. It is furthermore a reality that those shares that are paying dividends represent the major portion of market capitalisation; the shares that are excluded from our study will therefore provide limited investment opportunities to all but the small investor.

The data is also not free from survivorship bias, because only the shares that were still listed by 2010 are included in the sample. This is a possible shortcoming of the research, but it is also true that the majority of shares that delist are forced to do so due to non-compliance with exchange rules regarding the timely announcement of earnings and reporting standards. It can be argued that the information content of the earnings announcements of such shares is questionable and therefore it is deemed acceptable to exclude them from this research. The majority of companies that delist also do not pay dividends (which would have excluded them on the basis of nonavailability of data) and furthermore these shares represent a minor portion of market capitalisation. Their exclusion is therefore expected to have an insignificant effect on the outcomes of this research.

Pre-processing of the data included removal of outliers. The threshold above which data is excluded from the dataset was based on the deemed reliability of the available data ${ }^{1}$ and on the frequency of occurrence of extreme outliers. The thresholds were mostly chosen to exclude the data which fell outside 4 to 5 standard-deviations from the mean. Whenever an aggregated measure fell outside these 4 or 5 standard deviations from the mean, the specific observation was dropped from the dataset. This was done in order to reduce possible effects resulting from mergers/acquisitions, unbundling and disposal of assets and for which no data is available to make the necessary adjustments. The data samples removed in this way constitutes less than $0,1 \%$ of the total dataset. The data was however adjusted for all share splits and corporate actions for which sufficient data exists. Although as much care as possible has been taken to ensure the accuracy of the data used during calculations, some erroneous data samples will no doubt be included, but for the most part their impact on results and conclusions can be expected to be minimal.

All ratios used in the research are calculated using the last available month-end data before each announcement date. Unless otherwise stated all aggregate return data is equally weighted, due to the difficulty of weighting data according to market capitalisation that is dispersed through time. Dividends have been included in return series at the time of the

\footnotetext{
1 These exclusions were applied only for shares with known corporate actions and for which no data exist to implement corrections, as well as for those where the accuracy of the data is suspect.
} 
dividend pay-out date to form total return equally weighted portfolios whenever return data is aggregated $^{2}$.

Although the data is not representative of all companies that were listed on the JSE for the period 1991-2010, the sample period includes all possible market regimes or phases of the market business cycle to allow us to effectively test the stationarity and persistence of the post-earnings announcement drift effect over a representative data set.

\subsection{Methodology}

In order to establish when the announced earnings deviate from expectations and 'surprise' the market, it is necessary to define a way of calculating or estimating the expected earnings. The models used to define or estimate the expected earnings are called expectation models and previous research used several ways to estimate these expectation models (Foster et al., 1984). A favourite method used by researchers is the consensus estimates provided by data providers and sourced from analysts. Due to the lack of a historical database of consensus estimates before each earnings announcement, other expectation models are used in this research.

The following expectations models are used in this research. The first model uses the last previously announced EPS as the expected earnings. The change in EPS is thus used as a proxy for unexpected earnings. The normalised change in EPS for the $i$-th observation from period $t-1$ to period $t$ is defined as:

$\Delta \mathrm{EPS}_{\mathrm{i}, \mathrm{t}}=\frac{\mathrm{EPS}_{\mathrm{i}, \mathrm{t}}-\mathrm{EPS}_{\mathrm{i}, \mathrm{t}-1}}{\left|\mathrm{EPS}_{\mathrm{i}, \mathrm{t}-1}\right|}$

It should however be noted that the above definition of unexpected earnings (UE) is not necessarily measuring a surprise to the market, because the market's consensus earnings estimate may be correct no matter what the change in EPS is.

The second model uses cumulative security returns on the day of announcement as a proxy for unexpected earnings. Because some uncertainty exists about the time of the announcement and the day on which the market reacts thereto, the cumulative reaction on the days $[0 ;+2]$, with day 0 the announcement day, is used as an indication of the market's surprise to the announced earnings. In the rest of this paper this value

\footnotetext{
${ }^{2}$ This was done for the purpose of accurately simulating the effect of re-investing dividends only once they are paid out. The effect of later inclusion have however no effect on the measurement and significance of PEAD. The share prices drop by going ex-div and then recovers when the payment has been included, leaving it more or less where it started when going exdividend.
}

is called the initial reaction. The second earnings surprise proxy is therefore calculated as:

$I R_{i}=\sum_{t=0}^{2} R_{i, t}$

All returns are calculated as the natural logarithm of the ratio of the price to the previous period's price, also known as the continuous compound return:

$\mathrm{R}_{\mathrm{i}, \mathrm{t}}=\ln \left(\frac{\mathrm{P}_{\mathrm{i}, \mathrm{t}}}{\mathrm{P}_{\mathrm{i}, \mathrm{t}-1}}\right)$

Dividends are included by adding the dividend amount to the closing price $\left(\mathrm{P}_{\mathrm{i}, \mathrm{t}}\right)$ on the payout date and then calculating the natural logarithm of the returns as in equation 3 above.

The Post-Earnings Announcement Drift or the subsequent price drift after the initial reaction for observation i during period $t$ for the period subsequent to the announcement $(t=0)$ is calculated as:

$\mathrm{R}_{\mathrm{PEAD}, \mathrm{i}, \mathrm{t}}=\mathrm{R}_{\mathrm{i}, \mathrm{t}}, \forall \mathrm{t} \in[3 ; 120]$

The market return for observation $i$ for the same period subsequent to the announcement as in equation 1 is calculated as:

$\mathrm{R}_{\mathrm{PEADM}, \mathrm{i}, \mathrm{t}}=\mathrm{R}_{\mathrm{M}, \mathrm{t}}, \forall \mathrm{t} \in[3 ; 120]$

$R_{M, t}$ is the value weighted total market return including dividends.

Excess post-earnings announcement returns can be defined as $R_{P E A D, i, t}-R_{f}$, with $R_{f}$ the risk free rate of return. It must be determined if these excess returns exceed the risk adjusted returns that would be expected based on the systematic risk associated with holding the respective shares during the postannouncement drift periods. One approach to establish this would be to estimate $\alpha$ and $\beta$ for each share over a representative time period (say 5 years), and to compare returns over subsequent post-announcement periods with expected returns based on systematic risk as represented by the estimated value for $\beta$. However, as we cannot assume return volatility (and therefore systematic risk as represented by $\beta$ ) to be the same during the post-announcement periods as it would be for the share in general, we believe that it would not be correct to follow the above approach to assess PEAD return performance.

We therefore decided to rather follow a different approach, namely to compare the risk-adjusted returns during the post-announcement drift periods to market returns during the same periods. In order to determine systematic risk during the PEAD periods we estimated $\alpha$ and $\beta$ over the combined post-announcement drift periods and then determined whether actual returns 
during the PEAD periods were in excess of expected returns based on the PEAD $\beta$.

Using the market model we therefore regressed postearnings announcement excess returns against excess market returns to obtain the PEAD $\alpha$ and $\beta$ for each share, representing the behaviour of the respective shares, not in general, but specifically for the periods 3 to 120 days subsequent to earnings announcements:

$\mathrm{R}_{\mathrm{PEAD}, \mathrm{i}, \mathrm{t}}-\mathrm{R}_{\mathrm{f}}=\alpha_{\mathrm{PEAD}, \mathrm{i}}+\beta_{\mathrm{PEAD}, \mathrm{i}}\left(\mathrm{R}_{\mathrm{PEADM}, \mathrm{i}, \mathrm{t}}-\mathrm{R}_{\mathrm{f}}\right)+\varepsilon_{\mathrm{i}, \mathrm{t}}$

The parameters $\alpha_{\text {PEAD,i }}$ and $\beta_{\text {PEAD,i }}$ are calculated from a time-series regression of the individual observation's excess return $\left(R_{P E A D, i}-R_{f}\right)$ and the excess market return $\left(R_{P E A D M, i}-R_{f}\right)$ for the same time periods.

Due to the lack of available data covering the whole period and to simplify matters the risk-free rate $\left(\mathrm{R}_{\mathrm{f}}\right)$ was taken to be a constant throughout this research:

$\mathrm{R}_{\mathrm{f}}=0,04(4 \%$ per annum)

While it would have been more correct to use a varying measure for $R_{f}$ we argue that since $\mathrm{R}_{\mathrm{f}}$ is subtracted both from share specific and from market returns, a varying risk-free rate would have had a minimal impact on the resulting values of $\alpha$ and $\beta$.

Lastly we had to make a choice for the excess return performance measure. According to the portfolio performance measure proposed by Jensen (Jensen, 1968) $\beta_{\text {PEAD,i }}$ as estimated in Equation 6 above fully reflects the systematic market risk of the share during the post-announcement periods, and $\alpha_{\text {PEAD,i }}$ can therefore be regarded as the excess risk-adjusted post-earnings announcement returns. We thus use Jensen's alpha measure to investigate the PEAD performance of shares in subsequent sections of this paper.

\subsubsection{Investigating the PEAD anomaly}

The null hypothesis that is investigated in this research is as follows:

$\mathbf{H}_{0}$ : There is no relationship between unexpected earnings (earnings surprise as reflected by amongst others the initial return reaction over days 0 to 2 after the announcement) and subsequent post-earnings announcement returns (resulting from subsequent price drift over days 3 to 120 after the announcement) for the period 1991 to 2010 on the JSE.

Three sets of empirical tests are implemented to evaluate the null hypothesis. The relationship between unexpected earnings and post-earnings announcement returns, that is called the PEAD effect in this paper, is at the core of testing the null hypothesis. The results obtained from analysing the relationships between other anomaly variables and post-earnings announcement returns are however essential to establish whether the PEAD effect is truly an independent effect or if it is merely a manifestation of other well-known anomalies such as the momentum effect, the value effect or the size effect.

In order to perform the above empirical tests we need definitions for the following four variables: unexpected earnings; a value effect variable, a momentum variable and a size-effect or liquidity variable. Each of these variables will be evaluated as possible explanatory variables contributing to excess PEAD. As there are no universally agreed definitions for any of these, more than one definition is used to ensure that the possible impact of the respective variable is properly reflected. The definitions for the respective variables are as follows:

1. Unexpected earnings is represented by the two expectation models defined in the previous section:

- Initial Reaction (IR)

- Normalised change in earnings per share ( $\triangle \mathrm{EPS})$

2. The anomaly variables related to the measurement of the value effect:

- $\quad$ Earnings yield (EY)

- $\quad$ Dividend yield (DY)

- Book-to-market (B2M) ratio

3. The anomaly variables related to the momentum of the share price:

- $\quad$ The six month share price momentum (Mom6).

- The six month momentum of the value weighted market return (MS6).

- The six month share price momentum relative to the market (RS6).

- Drift in returns for the ten days prior to the earnings announcement (PreEAD).

4. The anomaly variables related to size and/or liquidity. The anomaly variables in this category are proxies for several related effects that have been widely studied in the literature; they are the size-effect or small firm effect, the neglected firm effect, liquidity effect and the low price effect. The variables used are

- The natural logarithm of the market capitalisation of a firm (MC).

- The share turnover as measured by the average monthly traded volume as a fraction of the number of issued shares for the past three months (ST3). 
- The natural logarithm of the absolute closing price (PC).

Analysts usually do not spend time analysing smaller firms and therefore they are somewhat neglected (Bodie et al., 2005). Institutional investment managers also tend to ignore shares with a very low absolute share price, the so-called penny shares; therefore they are also largely neglected. It is argued that this neglect leads to lower trading volume and thus lower liquidity. This forms the basis of the argument that low price, small size and low trading volume are related effects (Bodie et al., 2005).

Four size groups are used throughout this research. The groups corresponds with the 0-50, 51-75, 76-90 and $91-100^{\text {th }}$ percentile, the lowest $50 \%$ is classified as micro firms; the following $25 \%$ is classified as small firms, the next $15 \%$ as medium and the last $10 \%$ as large.

The three tests that are implemented to test the null hypothesis are

- cross-sectional correlation analysis,

- cross-sectional analysis by sorting and grouping and

- cross-sectional regression analysis.

Firstly the sample correlation coefficients are calculated between each of the variables in the abovementioned four groups of explanatory variables and the excess PEAD returns $\left(\alpha_{P E A D, i}\right)$.

Secondly, the data is sorted according to each of the explanatory variables and grouped into quartiles; the corresponding mean excess PEAD return $\left(\alpha_{\mathrm{PEAD}, \mathrm{i}}\right)$ of each quartile is then calculated and the difference between quartile and population average is tested for statistical significance.

The sorting and grouping technique is shown to be better at establishing the degree to which explanatory variables can be used to predict future extreme returns. As most investment strategies are only concerned with extreme behaviour, a variable that is successful at differentiating between the extremes in future returns is very valuable in designing an investment or trading strategy. Although the sample correlation coefficient is a good measure of the overall relationship between two variables, it is an average linear measure and thus not the preferred technique for establishing the strength of extreme and non-linear relationships. The sorting technique also does not assume normally distributed data.

The third technique involves cross-sectional regression of returns on predetermined attributes (i.e. the explanatory variables). Here the dependent variable is each security's excess PEAD return $\left(\alpha_{P E A D, i}\right)$ and the independent variables are its normalised exposures to the attributes (Johnson \& Wichern, 2007; Jacobs \& Levy, 1988).

All the variables in the four anomaly categories mentioned are used in the cross-sectional regression analysis. Each variable is normalised by subtracting its equally weighted mean $\mu_{\text {anomaly }}$ and dividing by its standard deviation $\sigma_{\text {anomaly }}$.

anomaly $_{\text {Normalised }}=\frac{\text { anomaly }-\mu_{\text {anomaly }}}{\sigma_{\text {anomaly }}}$

In addition to the 12 anomaly variables the following binary dummy variables will also be used.

- Nine industry categories - Shares on the AltX, venture capital, development capital and the JSE Africa boards are grouped together in one industry category. The other industry categories are: Basic Materials, Consumer Goods, Consumer Services, Financials, Health Care, Industrials, Oil \& Gas, Technology, and Telecommunications.

- The four seasons of the year to test the seasonality of the PEAD effect - Summer, Autumn, Winter and Spring.

In total there are 25 independent variables and one dependent variable $\alpha_{\text {PEAD,i }}$ the excess risk-adjusted post-earnings announcement returns for each security. The simplified regression model equation in vector form is thus:

$\alpha_{\mathrm{PEAD}, \mathrm{i}}=\lambda+\theta \mathrm{X}+\varepsilon_{\mathrm{i}}$

where

$\theta$ is a vector consisting of all the coefficients to each of the independent variables (column vectors) in the matrix $X$ and $\lambda$ is the model's intercept on the $y$-axis.

A multiple linear regression model where all explanatory variables are simultaneously regressed on the excess PEAD return to establish each factor's pure contribution is calculated using ordinary least squares estimation (Jacobs \& Levy, 1988; Johnson \& Wichern, 2007). The goal of the regression analysis is not to find the best explanatory model, but to analyse the pure contribution of each factor in explaining the excess PEAD return. Each regression coefficient represents the marginal return to a stock with an exposure to that factor of one cross-sectional standard deviation (resulting from the normalization of the explanatory variables).

The use of so many interrelated variables in a multiple regression raises the problem of multi-collinearity between the variables. When the explanatory variables 
in a multivariate regression are highly correlated with each other the estimated regression coefficients are not very stable and are highly dependent on model structure and the data on which it is estimated. The measures taken to address multi-collinearity are discussed in Section 4 under Cross-sectional Regression Analysis.

\section{$4 \quad$ RESULTS}

In this section the results obtained from analysing the returns for the 120 trading day (6 months) period after earnings releases (the [3; 120] period) are presented and discussed. The results of these analyses can reasonably be expected to provide evidence based on which the null hypothesis can either be accepted or rejected, i.e. whether or not the PEAD anomaly occurred on the JSE for the period 1991-2010.

\subsection{Equally weighted versus value weighted average returns}

The PEAD anomaly will be investigated by forming categories of observations as dictated by the values of the anomaly variables (e.g. by sorting shares according to anomaly variables values). The interaction between PEAD returns and anomaly variable values will then be determined by calculating the equally weighted excess returns within these categories of observations, and comparing PEAD returns in each category with equally weighted average PEAD returns for the relevant population. As the (equally weighted) excess PEAD returns (as reflected by the average over all observations of $\left.\alpha_{\text {PEAD, } i}\right)$ is however the result of regressions against value weighted market returns, it is necessary to first investigate the relationship between equally weighted and value weighted returns for the entire population.

Equally weighted average returns as observed over the post-announcement periods are displayed in Table 1. The equally weighted average nominal logarithmic returns for the 120 trading day (6 months) periods subsequent to earnings announcements for all the observations are 0,0628; if the three-day announcement returns (previously termed as the initial reaction) are included, it increases to 0,074 . It is just short of the 0,0766 average total return achieved by the value weighted market.

One would expect an average equally weighted excess risk-adjusted return of 0 if average returns are only explained by market risk and if each share's beta fully reflects the market risk of that share. The average equally weighted excess risk-adjusted return is however calculated to be 0,0207 , which is significantly different from zero. This could be attributed to the low average beta $(0,52)$ of the equally weighted PEAD returns estimated from a regression on the valueweighted market returns. The relatively low average beta of the equally weighted PEAD returns is in turn mainly attributable to the low estimated beta of the low liquidity and small cap stocks that carries higher relative weighting due to their large numbers. The higher than zero excess risk-adjusted PEAD returns could also be due to other risk related effects not captured by a single factor CAPM market model.

This higher-than-zero excess return for the return of the total sample poses a potential problem for the interpretation of the results obtained for specific categories of observations. One could argue that the problem could easily be fixed by weighting the respective stocks by market capitalisation (value). As mentioned in Section 3.1, it is however very difficult to form value weighted portfolios when the observations are dispersed through time, therefore we will have to live with the limitations of equally weighted returns.

The higher than zero equally weighted average excess PEAD return over all observations was therefore specifically taken into consideration when evaluating the results obtained for specific categories of observations as described in the rest of the paper. This was done by calculating all t-statistic values in the paper by using the equally weighted mean of the relevant population as reference rather than zero. As will be observed it will result in some t-statistic values that are opposite in sign compared to the underlying nominal parameter value (e.g. a sample average that is positive but lower than the respective population average, hence having a negative t-statistic).

\section{Table 1: Average returns for the post- announcement period}

\begin{tabular}{lc}
\hline & Average return \\
\hline EW PEAD & 0,0628 \\
Event + EW PEAD & 0,0740 \\
VW Total Return & 0,0766 \\
Excess risk-adjusted PEAD $\left(\alpha_{\text {PEAD }}\right)$ & 0,0207 \\
\hline
\end{tabular}

\subsection{Predictors of excess post-earnings announcement returns}

In this section the results from the analysis testing the relationship between post-earnings announcement returns and the anomaly variables will be presented. The main relationship under investigation in this research is that between unexpected earnings and the excess PEAD. The degree to which they are related is presented first; evidence whether or not the PEAD effect is a manifestation of other known anomalies follows subsequently.

We start the statistical analysis by calculating the sample correlation coefficients between the anomaly variables and the excess risk-adjusted postannouncement returns over the [3; 120] day period, which is estimated using the market model described in Section 3, equation 4. The sample correlation 
coefficient between the excess post-earnings announcement returns and each anomaly variable determines the strength of the relationship between the two variables and is presented in Table 2.

Table 2: Sample correlation coefficients between excess PEAD and anomaly variables

\begin{tabular}{lcr}
\hline & Correlation coefficient & t-Statistic \\
\hline IR & 0,0961 & 6,6041 \\
$\Delta$ EPS & 0,0609 & 3,5738 \\
MC & $-0,1089$ & $-7,2940$ \\
PC & $-0,1111$ & $-7,4491$ \\
ST3 & $-0,0534$ & $-3,5593$ \\
EY & 0,0866 & 5,1996 \\
DY & 0,0909 & 5,4630 \\
B2M & 0,0357 & 2,1320 \\
PreEAD & 0,0672 & 4,6125 \\
RS6 & 0,1117 & 7,4831 \\
Mom6 & 0,0906 & 6,0619 \\
MS6 & $-0,0135$ & $-0,8996$ \\
\hline
\end{tabular}

Both proxies for unexpected earnings are positively correlated with excess PEAD and the coefficients are significant at the $1 \%$ level. Excess PEAD returns are highly negatively correlated with all of the size-effect variables, namely the market capitalisation, the absolute price and the average share turnover of a firm. The calculated correlation is significant at the $1 \%$ level for all three variables. The relationship of the value effect as measured by earnings yield (EY) and dividend yield (DY) are both positively correlated with excess PEAD at the $1 \%$ level of significance. The positive correlation of the book-to-market ratio with excess PEAD is significant at the $5 \%$ level. All the momentum variables except the 6 month market momentum are positively correlated with excess PEAD at a $1 \%$ level of significance.

Testing the null hypothesis involves testing the strength of the relationship between the unexpected earnings (UE) and the subsequent excess returns (PEAD). The sample correlation coefficients clearly indicate that there is a strong relationship between UE and PEAD, but to reject the null hypothesis with confidence we need some further evidence, as the high correlation of excess PEAD with the other anomaly variables indicate that the relationship may just be a manifestation of other well-known anomalous effects.

\subsection{Unexpected earnings}
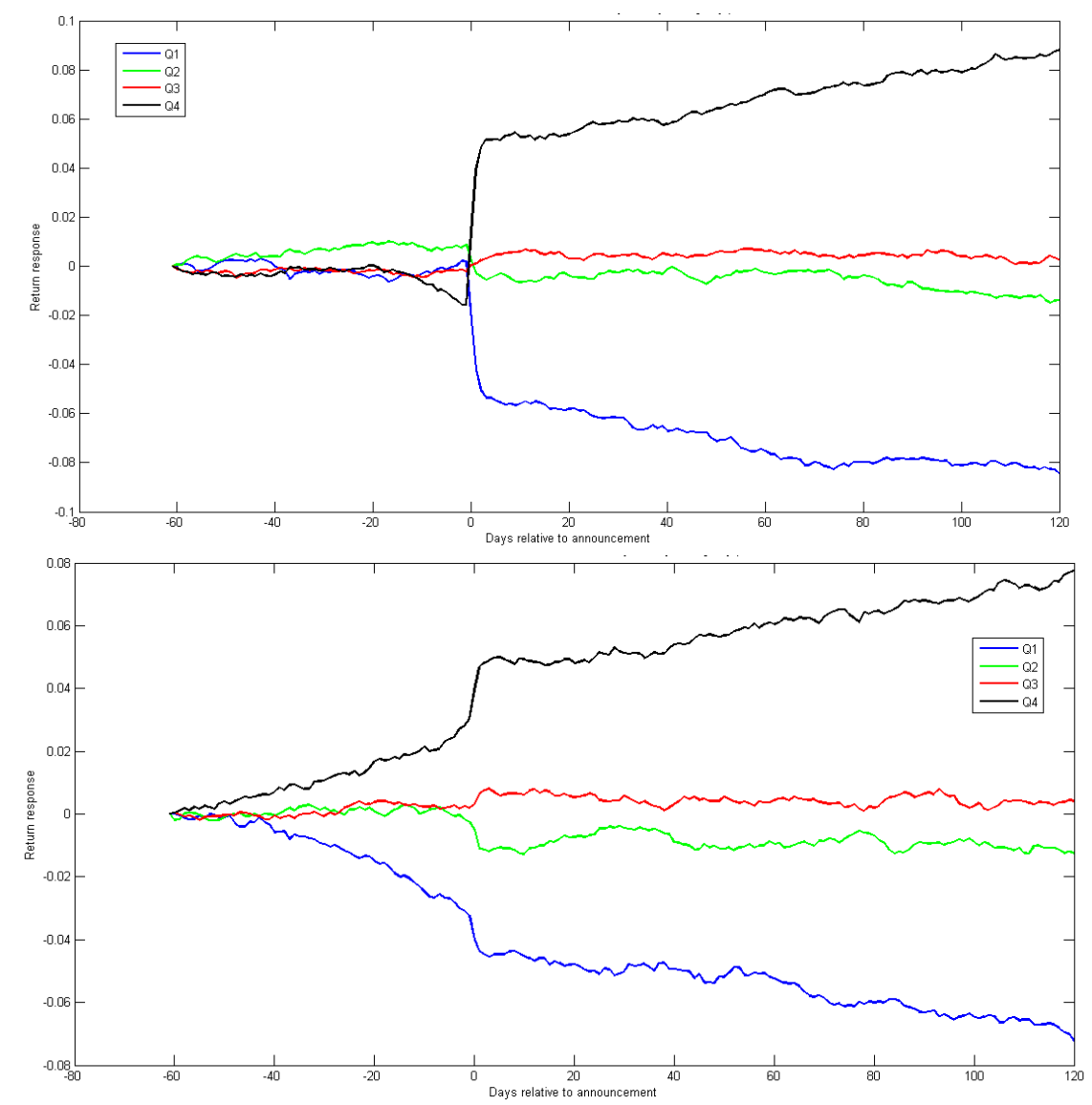

Figure 1: Cumulative market-adjusted return relative to the earnings announcements day for $\Delta \mathrm{EPS}$ quartiles (top) and IR quartiles (bottom) 
Figure 1 shows the cumulative market-adjusted return for the $[-60 ; 120]$ day period prior and subsequent to the earnings announcements. An interesting aspect of the response relevant to the current analysis is that for the bottom (top) $\triangle E P S$ quartile, the prices start to drift in the same direction as the $\triangle E P S$ response from approximately the $20^{\text {th }}$ day after the announcement up to the next announcement $( \pm 120$ days from the previous). This is a clear manifestation of the postearnings announcement drift (PEAD) anomaly.

Testing the predictive ability of the same variables by sorting shares based on each variable, grouping them into quartiles and calculating each group's corresponding excess PEAD returns reveals that the unexpected earnings as measured by IR (initial reaction) and $\triangle E P S$ are able to separate the winners from the losers as shown in Table 3. The bottom quartile of unexpected earnings as measured by IR experiences average excess PEAD return of $-0,0245$ which is statistically significant at the $1 \%$ level, while the top quartile experiences average excess PEAD return of 0,0566 which is also significant at the $1 \%$ level. This gives an average excess hedged return (taking a long position in the winning quartile and shorting the losing quartile) of 0,0811 before transaction costs for the 120 trading day period postannouncement. Although $\triangle E P S$ is also able to separate winners from losers, this is true to a lesser extent (lower t-statistics and smaller hedged returns).

While the above may be sufficient evidence to prove the significance of the relationship between unexpected earnings and PEAD, the question arises how stable (stationary) this relationship has been over the twenty years under study. In order to study this, the average cumulative return for the 120 day period after the announcement for each year and for each IR quartile are shown in Table 4 with the number of observations per year in the last column.

Table 3: PEAD returns corresponding to unexpected earning quartiles

\begin{tabular}{crr}
\hline Quartile & Mean excess return & t-Statistic \\
\hline IR & & \\
1 & $-0,0245$ & $-5,4645$ \\
2 & 0,0264 & 0,7439 \\
3 & 0,0163 & $-0,6178$ \\
4 & 0,0566 & 4,7533 \\
$\Delta$ EPS & & \\
1 & 0,0056 & $-1,7631$ \\
2 & 0,0268 & 0,7057 \\
3 & 0,0248 & 0,5827 \\
4 & 0,0446 & 2,7235 \\
\hline
\end{tabular}

The difference in the average value of Table 4 and the values in Table 3 is due to the different weighting each year carries in the total sample. The total number of observations per year is relatively small in the first decade compared to the second decade which thus carries a larger weighting. Hedged returns, although quite volatile, experienced only two negative years over the twenty year period, in 1998 during the Asian and emerging market crisis and again in 2009 during the global financial crisis, with an average excess return of 0,0877 for the six month post-announcement period.

\subsection{Size and liquidity effect}

We further investigate the relationship between size and PEAD. The cumulative return for the four size groups and the four $\triangle E P S$ quartiles is displayed in Figure 2.

Table 4: Excess PEAD returns for each year from 1991-2010 sorted by unexpected earnings quartile

\begin{tabular}{|c|c|c|c|c|c|c|c|c|c|}
\hline Year & Ret Q1 & t-stat & Ret Q2 & $\begin{array}{c}\text { Quartile } \\
\text { t-stat }\end{array}$ & Ret Q3 & t-stat & Ret Q4 & t-stat & \# \\
\hline 1991 & 0,0341 & $-0,1168$ & 0,0336 & $-0,1217$ & 0,0214 & $-0,2909$ & 0,2100 & 99,999 & 13 \\
\hline 1992 & 0,0149 & $-0,0772$ & 0,0013 & $-0,5078$ & 0,1043 & 2,3806 & 0,0794 & 0,3941 & 108 \\
\hline 1993 & 0,0139 & $-1,0981$ & 0,1251 & 0,3655 & 0,1028 & $-0,2543$ & 0,1808 & 0,7732 & 112 \\
\hline 1994 & 0,0735 & $-0,1207$ & 0,1166 & 1,2885 & $-0,0423$ & $-2,7157$ & 0,0765 & $-0,0985$ & 121 \\
\hline 1995 & 0,1168 & $-0,0828$ & 0,0980 & $-0,9737$ & 0,1559 & 0,5447 & 0,3036 & 2,3233 & 144 \\
\hline 1996 & $-0,0473$ & $-0,0996$ & $-0,0350$ & 0,2479 & $-0,0636$ & $-0,5034$ & $-0,0092$ & 0,3070 & 150 \\
\hline 1997 & $-0,0937$ & $-1,8769$ & $-0,0016$ & 0,3431 & 0,0051 & 0,3969 & 0,0875 & 1,7630 & 155 \\
\hline 1998 & $-0,1646$ & 0,2994 & $-0,1700$ & 0,1741 & $-0,1811$ & $-0,0477$ & $-0,1975$ & $-0,4544$ & 172 \\
\hline 1999 & $-0,0422$ & $-1,0528$ & $-0,0365$ & $-0,6814$ & 0,0384 & 0,6604 & 0,0470 & 1,2132 & 187 \\
\hline 2000 & $-0,0765$ & $-1,2076$ & $-0,0528$ & $-0,4328$ & $-0,0148$ & 0,4491 & 0,0338 & 2,3155 & 211 \\
\hline 2001 & 0,0393 & 0,9747 & $-0,0236$ & $-1,2753$ & $-0,0484$ & $-1,5198$ & 0,0480 & 1,4316 & 233 \\
\hline 2002 & $-0,0285$ & $-2,4582$ & 0,0441 & 0,1754 & 0,0131 & $-0,9895$ & 0,0950 & 2,1188 & 249 \\
\hline 2003 & 0,0348 & $-2,7276$ & 0,1132 & 0,1985 & 0,1223 & 0,5610 & 0,1548 & 1,9776 & 260 \\
\hline 2004 & 0,0377 & $-3,6360$ & 0,1566 & 0,6549 & 0,1117 & $-0,7225$ & 0,2117 & 3,2083 & 270 \\
\hline 2005 & 0,0635 & $-1,6448$ & 0,1216 & 0,8056 & 0,0854 & $-1,1861$ & 0,1480 & 1,8381 & 293 \\
\hline 2006 & 0,0175 & $-1,3241$ & 0,0559 & 0,4092 & 0,0630 & 0,7890 & 0,0507 & 0,1887 & 304 \\
\hline 2007 & $-0,1271$ & $-1,4768$ & $-0,0997$ & $-0,3053$ & $-0,0967$ & $-0,3206$ & $-0,0246$ & 2,4397 & 328 \\
\hline 2008 & $-0,1230$ & $-0,4760$ & $-0,1667$ & $-1,4934$ & $-0,0808$ & 0,9141 & $-0,0627$ & 1,6215 & 351 \\
\hline 2009 & 0,0924 & 1,2989 & 0,0370 & $-1,5187$ & 0,0435 & $-1,4627$ & 0,0902 & 1,2687 & 339 \\
\hline 2010 & $-0,0186$ & $-1,7750$ & 0,0380 & 0,9536 & 0,0183 & $-0,2328$ & 0,0479 & 1,7713 & 338 \\
\hline Avg & $-0,0092$ & $-0,9339$ & 0,0178 & $-0,0847$ & 0,0179 & $-0,1775$ & 0,0786 & 6,3200 & \\
\hline
\end{tabular}



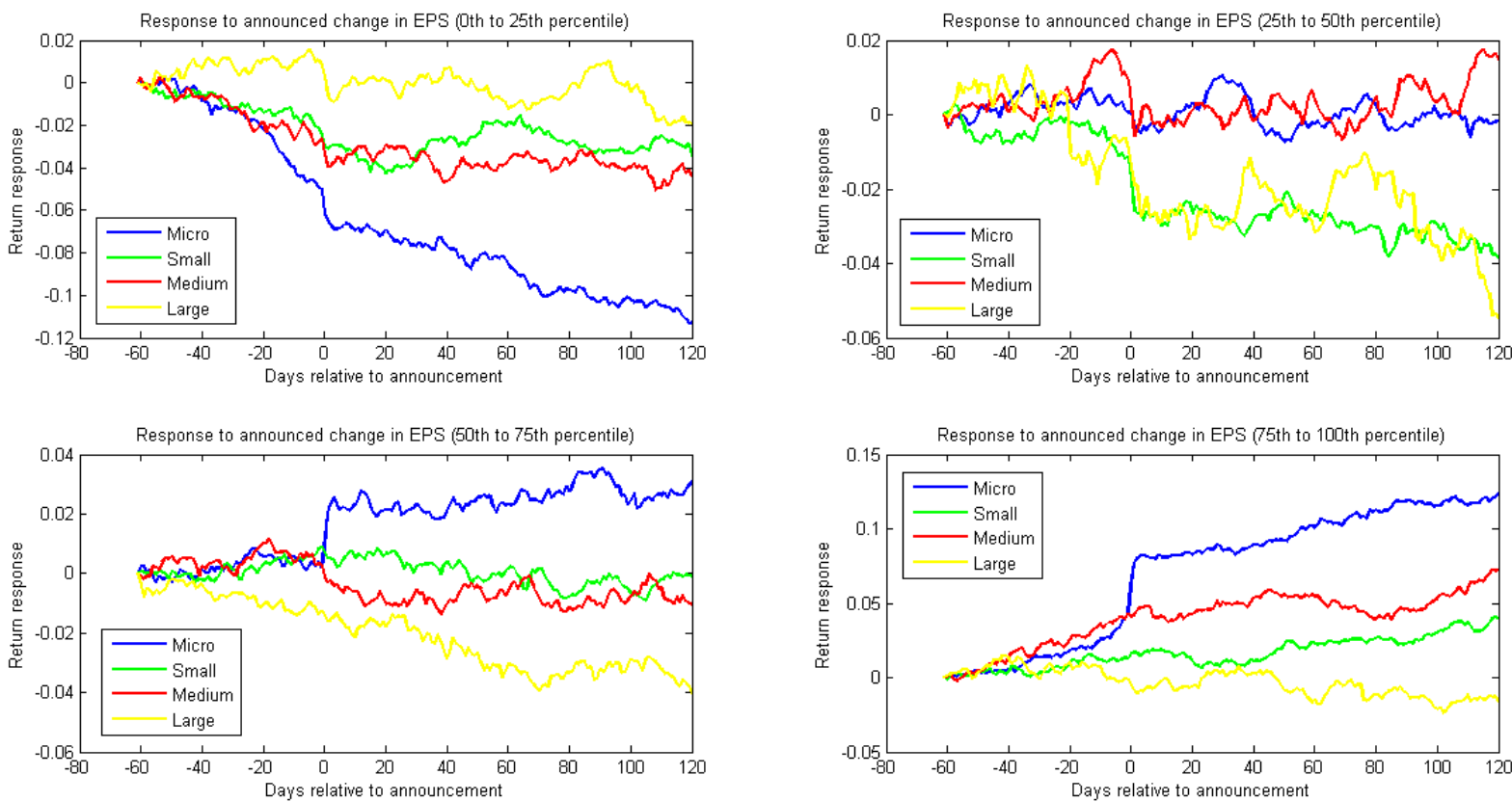

Figure 2: Cumulative market-adjusted return relative to the earnings announcement day for different $\Delta$ EPS and size quartiles

The high correlation between PEAD and size poses the question whether the PEAD effect is not merely a manifestation of the size effect.

Before the question is answered we first take a further look at the ability of the three size and liquidity measures to separate the winners from the losers. The sample was sorted by size into four groups as described in Section 3. Share turnover (ST3), and the log of the absolute closing share price (PC) are sorted and grouped into quartiles giving the results as shown in Table 5.

Table 5: PEAD returns corresponding to size/liquidity quartiles

\begin{tabular}{|c|c|c|}
\hline Quartile & Mean excess return & t-Statistic \\
\hline \multicolumn{3}{|l|}{ Market Cap } \\
\hline Micro & 0,0359 & 2,4092 \\
\hline Small & 0,0170 & $-0,5442$ \\
\hline Medium & 0,0075 & $-1,6848$ \\
\hline Large & $-0,0438$ & $-7,1816$ \\
\hline \multicolumn{3}{|l|}{ ST3 } \\
\hline 1 & 0,0431 & 3,2448 \\
\hline 2 & 0,0035 & $-1,6358$ \\
\hline 3 & 0,0102 & $-1,4164$ \\
\hline 4 & 0,0018 & $-2,5453$ \\
\hline \multicolumn{3}{|l|}{ PC } \\
\hline 1 & 0,0560 & 3,6312 \\
\hline 2 & 0,0212 & 0,0618 \\
\hline 3 & 0,0136 & $-1,0376$ \\
\hline 4 & $-0,0149$ & $-5,7497$ \\
\hline
\end{tabular}

It is clear that all of these variables are statistically significant predictors of excess PEAD returns and thus size and liquidity as measured by these three variables are good at separating winners from losers. The margin by which large capitalisation shares underperform the average after earnings announcements is noteworthy.

To investigate the effect of size on the relationship between unexpected earnings and postannouncement returns, the sample was sorted by size and grouped into the four size groups. Each group was then further sorted by unexpected earnings as measured by IR and divided into quartiles. The results obtained are presented in Table 6.

Table 6: PEAD returns grouped by size and divided into unexpected earnings quartiles

\begin{tabular}{ccc}
\hline Quartile & Mean excess return & t-Statistic \\
\hline MicroCap & & \\
1 & $-0,0294$ & $-4,0448$ \\
2 & 0,0413 & 0,5066 \\
3 & 0,0343 & $-0,1175$ \\
4 & 0,0748 & 3,3647 \\
SmallCap & & \\
1 & $-0,006$ & $-1,7212$ \\
2 & 0,015 & $-0,1412$ \\
3 & 0,0161 & $-0,0701$ \\
4 & 0,0516 & 2,6547 \\
MidCap & & \\
1 & $-0,0133$ & $-1,2389$ \\
2 & $-0,0105$ & $-1,0556$ \\
3 & 0,0206 & 1,1134 \\
4 & 0,0383 & 1,878 \\
LargeCap & & \\
1 & $-0,0598$ & $-0,9784$ \\
2 & $-0,053$ & $-0,3471$ \\
3 & $-0,0429$ & 0,0685 \\
4 & $-0,0145$ & 1,5594 \\
\hline
\end{tabular}


The results indicate that unexpected earnings as measured by IR are still able to separate winners from losers at the $10 \%$ level of significance. The hedged returns for all four size groups are significant at the 5\% level at least. When one looks at the hedged returns in the different size groups it is clear that the PEAD effect is more pronounced for the micro capitalisation shares,
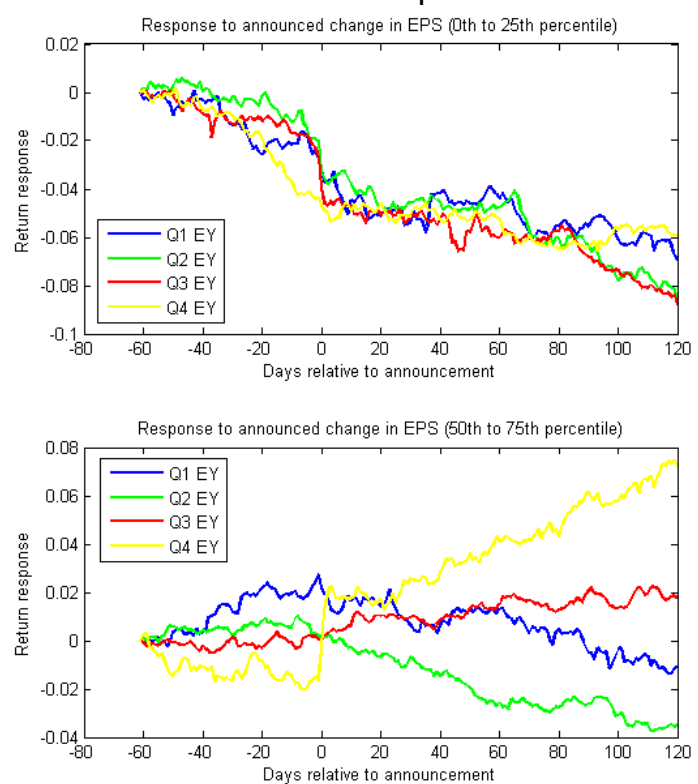

but the ability of unexpected earnings to separate winners from losers irrespective of size group provides evidence that the PEAD effect is not predominantly a size effect.
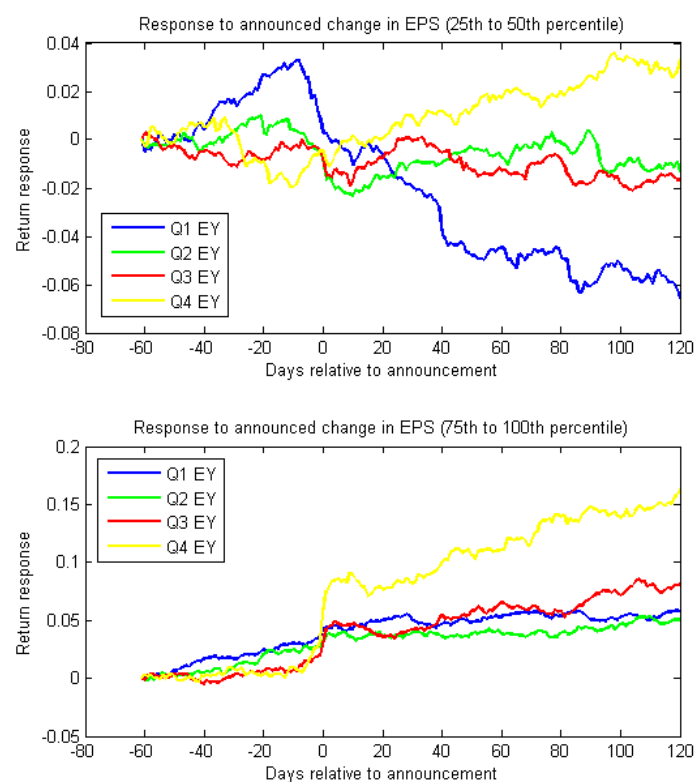

Figure 3: Cumulative market-adjusted return relative to the earnings announcement day for different $\Delta$ EPS and EY quartiles

\subsection{Value effect}

The cumulative market-adjusted return for the different value effect $(E Y)$ quartiles and the four $\triangle E P S$ quartiles is displayed in Figure 3.

Table 7: Excess PEAD returns corresponding to value measure quartiles

\begin{tabular}{rcc}
\hline & Mean Excess Return & t-Statistic \\
\hline B2M & & \\
1 & 0,0006 & $-2,3313$ \\
2 & 0,0184 & $-0,2964$ \\
3 & 0,0171 & $-0,4586$ \\
4 & 0,0583 & 4,3283 \\
DY $_{1}$ & & \\
2 & 0,0104 & $-1,1212$ \\
3 & $-0,0015$ & $-2,8405$ \\
4 & 0,0293 & 1,167 \\
EY $^{1}$ & 0,0621 & 5,3486 \\
1 & & \\
2 & $-0,0043$ & $-2,8441$ \\
3 & 0,0163 & $-0,6151$ \\
4 & 0,0249 & 0,5504 \\
\hline
\end{tabular}

From the cross-sectional analysis results in Table 7 it is evident that all value measures are statistically significant predictors of excess PEAD return at the $1 \%$ level of significance for the upper quartile, however only B2M and EY are statistically significant predictors for the lower quartile.
Table 8: PEAD returns grouped by quartiles which is further divided into unexpected earnings quartiles

\begin{tabular}{ccc}
\hline & Mean excess return & t-Statistic \\
\hline$<\mathbf{2 5 \%}$ EY & $-0,0502$ & $-2,4876$ \\
1 & $-0,0035$ & 0,0298 \\
2 & 0,0235 & 1,9079 \\
3 & 0,0130 & 0,8954 \\
4 & & \\
$\mathbf{2 6 - 5 0 \%}$ EY & 0,0025 & $-0,8995$ \\
1 & 0,0044 & $-0,7724$ \\
2 & 0,0042 & $-0,883$ \\
3 & 0,0601 & 2,8644 \\
4 & & \\
$\mathbf{5 1 - 7 5 \%}$ EY & $-0,0168$ & $-2,8381$ \\
1 & 0,0470 & 1,3848 \\
2 & 0,0085 & $-0,9565$ \\
3 & 0,0580 & 2,2976 \\
4 & & \\
$\mathbf{7 6 - 1 0 0 \%}$ EY & 0,0152 & $-2,4315$ \\
1 & 0,0692 & 0,4692 \\
2 & 0,0615 & 0,0640 \\
3 & 0,0886 & 2,010 \\
4 & &
\end{tabular}

The best discriminator between winners and losers from the value effect group of measures (EY) is used to investigate the impact of the value effect on the relationship between unexpected earnings and postannouncement returns. The sample was sorted by EY and grouped into quartiles and each group is further 
sorted by unexpected earnings as measured by IR and divided into quartiles.

After sorting by $E Y$, the unexpected earnings measure $(\mathrm{IR})$ is still able to separate winners from losers in each value quartile. The top IR quartile in the $1^{\text {st }} E Y$ quartile and the bottom IR quartile in the $2^{\text {nd }} E Y$ quartile is however not significantly different from the mean of
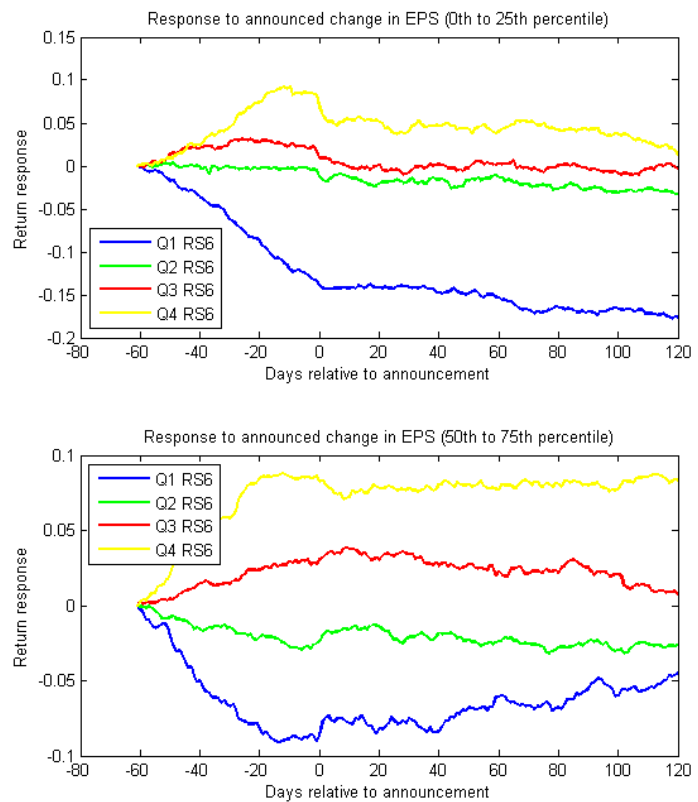

each respective EY quartile. For all other EY quartiles and IR extremes $\left(1^{\text {st }}\right.$ and $4^{\text {th }}$ quartile), the values are significant at not less than the $5 \%$ level. The evidence suggests that the relationship between unexpected earnings and PEAD is not predominantly a value effect, but that value is significantly related to excess PEAD returns.
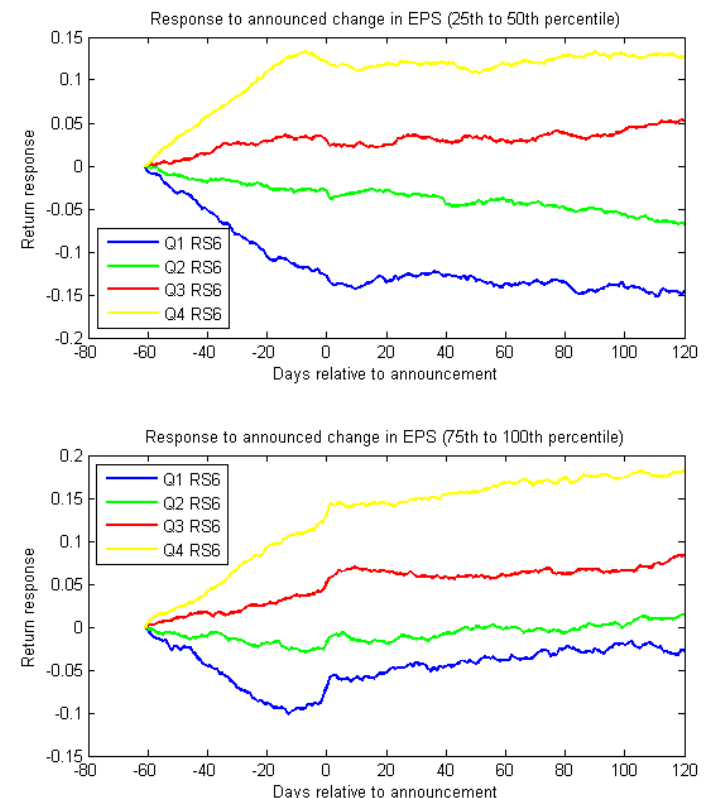

Figure 4: Cumulative market-adjusted return relative to the earnings announcement day for different $\Delta E P S$ and momentum quartiles

\subsection{Momentum effect}

The cumulative market-adjusted return for the different momentum (RS6) quartiles and the four $\triangle \mathrm{EPS}$ quartiles is displayed in Figure 4.

Sorting by momentum and grouping into quartiles reveals that RS6 best separates winners from losers with a hedged return of 0,0717 . Although the 10 day momentum prior to earnings announcements (PreEAD) is significantly correlated with excess PEAD, it is a relatively weak variable to separate the winners of excess PEAD returns from the losers.

Each sorted quartile of the best predictor of excess returns selected from the momentum group (RS6) was further grouped into IR quartiles. The results in Table 10 indicate that for each momentum quartile the unexpected earnings separate winners from losers. The hedged returns for each momentum quartile is on average higher after further sorting and grouping by unexpected earnings, than using any of the momentum measures alone.
Table 9: PEAD returns corresponding to momentum quartiles

\begin{tabular}{|c|c|c|}
\hline & Mean excess return & t-Statistic \\
\hline \multicolumn{3}{|l|}{ PreEAD } \\
\hline 1 & $-0,0133$ & $-3,8050$ \\
\hline 2 & 0,0273 & 0,9277 \\
\hline 3 & 0,0388 & 2,5293 \\
\hline 4 & 0,0222 & 0,1996 \\
\hline \multicolumn{3}{|l|}{ RS6 } \\
\hline 1 & $-0,0191$ & $-4,4874$ \\
\hline 2 & 0,0047 & $-2,2494$ \\
\hline 3 & 0,0396 & 2,8103 \\
\hline 4 & 0,0526 & 3,9168 \\
\hline \multicolumn{3}{|l|}{ Mom6 } \\
\hline 1 & $-0,0160$ & $-4,3279$ \\
\hline 2 & 0,0081 & $-1,5873$ \\
\hline 3 & 0,0445 & 3,5395 \\
\hline 4 & 0,0412 & 2,6611 \\
\hline \multicolumn{3}{|l|}{ MS6 } \\
\hline 1 & 0,0253 & 0,5701 \\
\hline 2 & 0,0144 & $-0,7860$ \\
\hline 3 & 0,0163 & $-0,5650$ \\
\hline 4 & 0,0197 & $-0,1311$ \\
\hline
\end{tabular}

This establishes that the PEAD anomaly is not a manifestation of the momentum effect, but that the inclusion of a momentum filter helps to further separate the winners from the losers of excess PEAD returns. 
Table 10: PEAD returns grouped by momentum quartiles with each further divided into unexpected earnings quartiles

\begin{tabular}{|c|c|c|}
\hline & Mean excess return & t-Statistic \\
\hline \multicolumn{3}{|l|}{$<25 \%$ RS6 } \\
\hline 1 & $-0,0668$ & $-2,4528$ \\
\hline 2 & $-0,0049$ & 0,8971 \\
\hline 3 & $-0,0144$ & 0,3132 \\
\hline 4 & 0,0081 & 1,6457 \\
\hline \multicolumn{3}{|c|}{$26-50 \%$ RS6 } \\
\hline 1 & $-0,0471$ & $-3,4641$ \\
\hline 2 & 0,0075 & 0,1782 \\
\hline 3 & 0,0213 & 1,5016 \\
\hline 4 & 0,0455 & 2,8248 \\
\hline \multicolumn{3}{|c|}{$51-75 \%$ RS6 } \\
\hline 1 & 0,0091 & $-2,0572$ \\
\hline 2 & 0,0493 & 0,7203 \\
\hline 3 & 0,0320 & $-0,6172$ \\
\hline 4 & 0,0597 & 1,5778 \\
\hline \multicolumn{3}{|c|}{$76-100 \%$ RS6 } \\
\hline 1 & 0,0157 & $-2,3658$ \\
\hline 2 & 0,0499 & $-0,1927$ \\
\hline 3 & 0,0233 & $-1,7214$ \\
\hline 4 & 0,1167 & 4,2106 \\
\hline
\end{tabular}

The price-reversal anomaly is also investigated to see if the short-term momentum (PreEAD) before an earnings announcement reverses depending on the outcome of the announcement. The results in Table 11 shows that for the bottom $50 \%$ of pre-announcement returns (PreEAD) the excess PEAD is positive for all quartiles of earnings surprises, thus indicating signs of price reversal. The top (bottom) quartile of earnings surprise (IR) for the bottom (top) quartile of PreEAD shows that the price-reversal anomaly exists on the JSE and that its occurrence around earnings announcements is statistically significant in the extreme quartiles.

The results obtained thus far indicate that unexpected earnings is a predictor of excess post-earnings announcement drift and that it is not a manifestation of any of the known anomalies, namely the size effect, the value effect or the momentum effect. The anomalies are however all correlated with unexpected earnings to some degree, but the fact that they all pronounce the excess returns indicate that they each provide additional information.

The stability of each variable's ability to separate winners from losers for each year from 1991-2010 is summarized in the box plot in Figure 5 and Table 12. It shows the median and variability (minimum and maximum annual values) of hedged returns over the 20 years. In terms of average hedged returns for the 6 month period subsequent to earnings announcements, $\mathrm{IR}$ and market cap are the leading contenders, but when one also takes variability into account, IR is the runaway leader in hedged returns which is highlighted by its corresponding t-statistic of 5,82.
Table 11: PEAD returns grouped by preannouncement drift quartiles with each further divided into unexpected earnings quartiles (IR)

\begin{tabular}{ccc}
\hline & Mean excess return & t-Statistic \\
\hline$<\mathbf{2 5 \%}$ PreEAD & 0,0049 & $-1,3255$ \\
1 & 0,0053 & $-1,2514$ \\
2 & 0,0128 & $-0,8423$ \\
3 & $\mathbf{0 , 0 9 2 3}$ & $\mathbf{3 , 7 0 2}$ \\
4 & & \\
$\mathbf{2 6 - 5 0 \%}$ PreEAD & 0,0064 & $-0,9040$ \\
1 & 0,0229 & $-0,2952$ \\
2 & 0,0283 & 0,0346 \\
3 & 0,0584 & 1,3628 \\
4 & & \\
$\mathbf{5 1 - 7 5 \%}$ PreEAD & $-0,0591$ & $-1,6504$ \\
1 & $-0,0304$ & $-0,4735$ \\
2 & $-0,0184$ & $-0,0009$ \\
4 & 0,0404 & 2,5232 \\
1 & & \\
2 & $-\mathbf{0 , 0 3 0 4}$ & $\mathbf{- 4 , 9 7 0 2}$ \\
3 & 0,0478 & 2,5597 \\
4 & 0,0230 & 0,1315 \\
$\mathbf{7 6 - 1 0 0 \%}$ PreEAD & 0,0472 & 2,5699 \\
\hline
\end{tabular}

The same data as in Figure 5 is presented in Figure 6 where the average hedged risk-adjusted return over the 20 years is plotted versus the standard deviation. The size of the circles is the return to risk ratio ${ }^{3}$. IR clearly stands out above the other anomaly variable contenders, for whom the relation of return versus risk is almost linear.

It can be argued that all the anomaly variables represent a risk-factor not captured by the single factor CAPM. If one makes this assumption and would further adjust the returns by subtracting the average linear relation between annual variation and average hedged excess PEAD returns, the excess return related to IR still stands out. Considering the combined evidence presented by the above analyses it can be argued that the relation between IR and excess PEAD return is not due to an uncaptured risk effect, but represents a clear violation of market efficiency and may present an exploitable profit opportunity.

To further analyse whether PEAD is independent from other effects a multivariate linear regression analysis is performed to disentangle the excess return uniquely attributable to each anomaly variable.

\subsection{Cross-sectional regression analysis}

The excess PEAD returns is used as the dependent variable and the entire group of anomaly variables (and others mentioned in Section 3) as independent variables.

Before the results are presented the measures taken to address multi-collinearity are discussed. These measures involve calculating cross-correlations, fitting the model on subsets of the data and removing variables to test the variance of coefficients.

\footnotetext{
${ }^{3}$ Modified Sharpe ratio with a risk-free rate of 0 .
} 


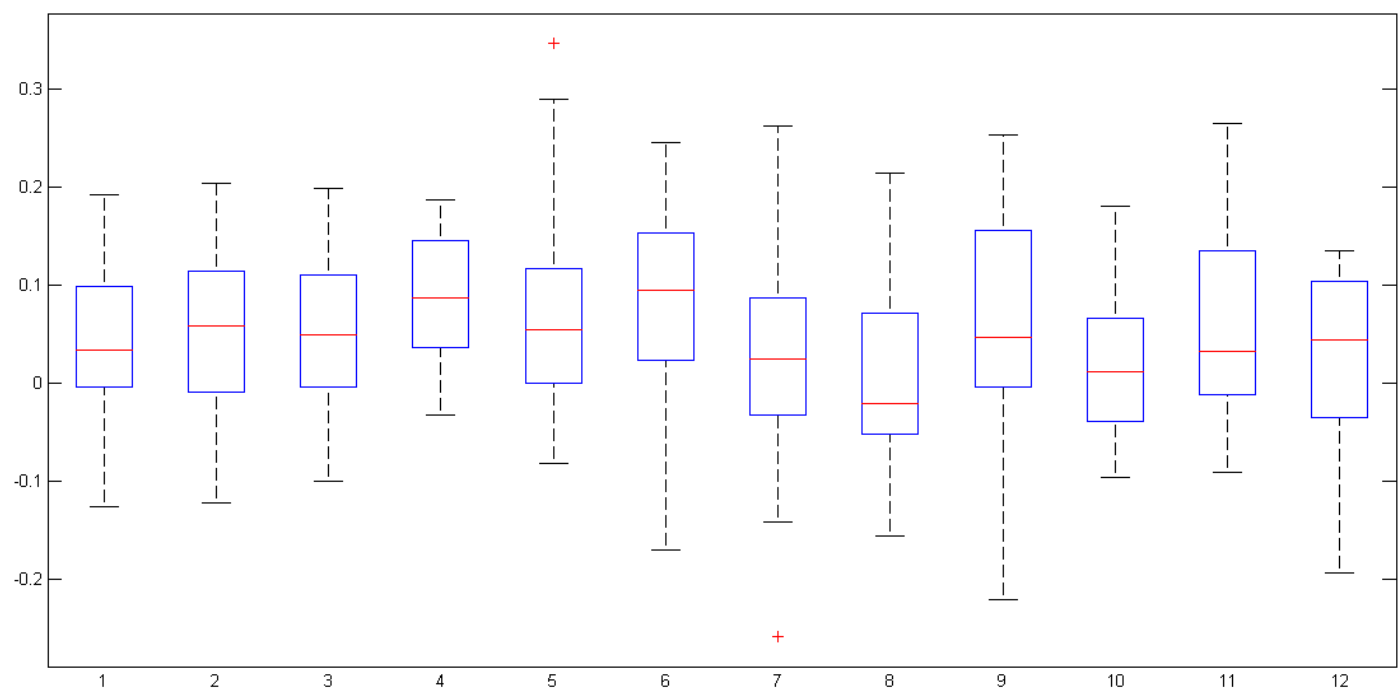

Figure 5: Boxplot of hedged returns for the period from 1991-2010, the data is shown in Table 12.

Table 12: Data accompanying boxplot in Figure 5

\begin{tabular}{|c|c|c|c|c|c|c|c|c|c|c|c|c|}
\hline & $\begin{array}{c}1 \\
\text { B2M }\end{array}$ & $\begin{array}{c}2 \\
\text { DY }\end{array}$ & $\begin{array}{c}3 \\
\Delta \text { EPS }\end{array}$ & $\begin{array}{c}4 \\
\text { IR }\end{array}$ & $\begin{array}{c}5 \\
E Y\end{array}$ & $\begin{array}{c}6 \\
M C\end{array}$ & $\begin{array}{c}7 \\
\text { Mom6 }\end{array}$ & $\begin{array}{c}8 \\
\text { MS6 }\end{array}$ & $\begin{array}{c}9 \\
P C\end{array}$ & $\begin{array}{c}10 \\
\text { PreEAD }\end{array}$ & $\begin{array}{c}11 \\
\text { RS6 }\end{array}$ & $\begin{array}{c}12 \\
\text { ST3 }\end{array}$ \\
\hline Average & 0,048 & 0,049 & 0,052 & 0,088 & 0,069 & 0,082 & 0,030 & $-0,007$ & 0,068 & 0,025 & 0,065 & 0,024 \\
\hline Std dev & 0,079 & 0,089 & 0,081 & 0,067 & 0,107 & 0,120 & 0,122 & 0,093 & 0,124 & 0,078 & 0,103 & 0,092 \\
\hline t-statistic & 2,75 & 2,45 & 2,06 & 5,82 & 2,89 & 3,06 & 1,11 & $-0,33$ & 2,45 & 1,44 & 2,81 & 1,17 \\
\hline
\end{tabular}

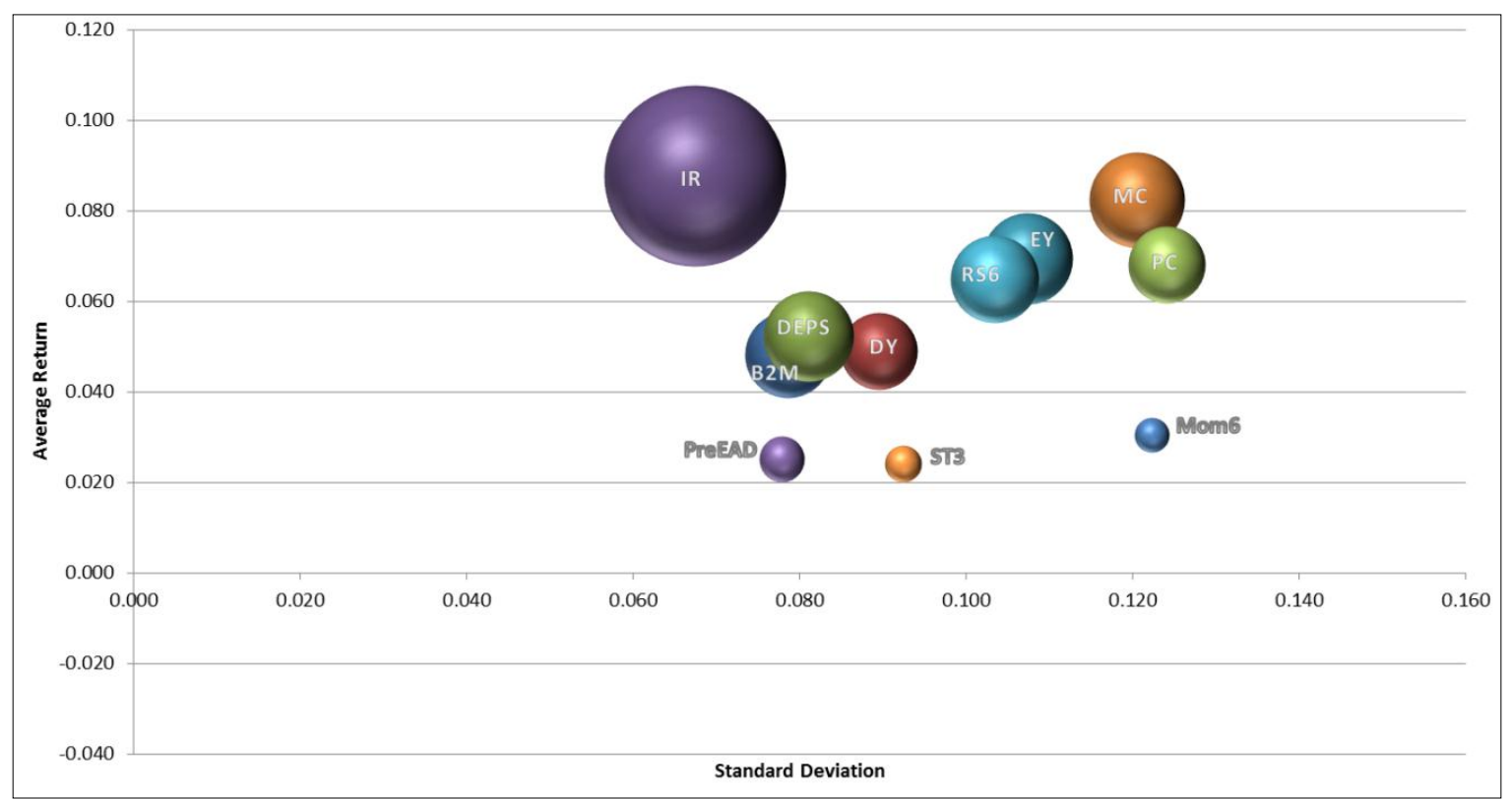

Figure 6: Average return vs. standard deviation of hedged returns for the period 1991-2010

The obvious sources of perfect multi-collinearity are the binary dummy variables which together are linearly dependent on the constant term in the regression model. One variable from the seasons and one from the industry sectors were removed. They are selected to minimise the loss of information:
- The summer season, because it represents the time of year with the fewest announcements.

- The industry category that contained all the companies on the development boards of the JSE (AltX, Venture Capital, Development Capital and the JSE Africa board), which is highly correlated 
with market capitalisation and therefore it is argued that the information is already captured.

A third variable, the 6 month momentum (Mom6) is also removed. By definition it is the sum of the relative momentum (RS6) and the market momentum (MS6) and therefore linearly dependent on these two variables.

Another source of multi-collinearity identified is the correlation between the market capitalisation and the price of shares with a sample correlation coefficient of $79 \%$.

The calculated coefficients from the cross-sectional regression analysis excluding the price variable are shown in Table 13. When the price variable is removed the coefficients are more stable and the attribution to market capitalisation is $-0,0196$ which is significant at the $1 \%$ level. The results from the regression analysis indicate that smaller firms on average earn higher excess returns which are in agreement with the results from the correlation and cross-sectional sort analysis.

\section{Table 13: Cross-sectional regression coefficients}

\begin{tabular}{lcc}
\hline Anomaly & Average & t-Statistic \\
\hline$\Delta$ EPS & 0,0128 & 3,2255 \\
IR & 0,0197 & 6,7452 \\
EY & 0,0177 & 4,6418 \\
DY & 0,0196 & 5,1571 \\
B2M & 0,0002 & 0,0410 \\
MarketCap & $-0,0196$ & $-6,3594$ \\
ST3 & 0,0013 & 0,4201 \\
PreEAD & 0,0129 & 4,4512 \\
RS6 & 0,0306 & 9,9471 \\
MS6 & 0,0063 & 2,0564 \\
Autumn & 0,0094 & 0,7874 \\
Winter & 0,0329 & 2,3502 \\
Spring & 0,0061 & 0,5163 \\
Basic Materials & 0,0154 & 0,8092 \\
Consumer Goods & 0,0310 & 1,1685 \\
Consumer Services & 0,0461 & 2,4832 \\
Financials & 0,0287 & 2,0249 \\
Health Care & 0,0802 & 0,5989 \\
Industrials & $-0,0138$ & $-0,9285$ \\
Oil \& Gas & 0,0892 & 0,2798 \\
Technology & $-0,0053$ & $-0,0571$ \\
Telecommunications & 0,0219 & 0,1097 \\
\hline
\end{tabular}

The coefficients can be interpreted as the marginal excess return to a share with an exposure to that factor of one cross-sectional standard deviation while the exposure to all other variables is neutral. It is best explained by an example: say the EY distribution among all shares has an average of 10 and a standard deviation of 1 at any particular time, then a factor coefficient of 0,02 means that a share with an EY of 11 would outperform the market by $0,02(2 \%)$ on a riskadjusted basis.

The coefficients of all the anomaly variables in Table 13 were found to be stable. The coefficient values of the dummy variables are however found to be more sensitive to changes in model structure and underlying data, but most are also not found to be statistically significant. Firms in the consumer services and financial industry categories are expected to earn excess PEAD returns of 0,0461 and 0,0287 respectively which is statistically significant at the $1 \%$ and $5 \%$ level. The exact coefficient values shouldn't be relied upon, but should rather be compared relative to those of other sectors.

Unexpected earnings as measured by $\triangle \mathrm{EPS}$ and IR both contribute to excess PEAD with $t$-statistics of 3,2255 and 6,7452 respectively, thus the null hypothesis $\left(\mathbf{H}_{0}\right)$ that there is no relationship between unexpected earnings (earnings surprise) and subsequent post-earnings announcement returns for the period 1991 to 2010 on the JSE can be rejected with confidence. The results indicate that the PEAD anomaly exists independently of the value, size and momentum effects and that it is statistically significant. It is also interesting to note that both $\triangle \mathrm{EPS}$ and IR are uniquely contributing to the prediction of excess return; they thus each contain independent information that is relevant to price formation for the six month period subsequent to earnings announcements.

The price and size proxies are collinear and the unique attribution to share turnover (liquidity) is negligible. Thus the size and liquidity effects are effectively captured by market capitalisation alone.

The value effect represented by EY and DY is also both independently contributing to excess postearnings announcement drift with t-statistics of 4,6418 and 5,1571 respectively. The payoff due to the two momentum variables, PreEAD and RS6, is 0,0129 ( $\mathrm{t}$ statistic of 4,4512) and 0,0306 (t-statistic of 9,9471) respectively. It is evident that the relative momentum (RS6) for the six months prior to the announcement on average persists for the six months subsequent to the announcement to a significant degree.

According to the $\mathrm{R}^{2}$-statistic the regression model only explains about $5,7 \%$ of the variance in excess returns. While the high level of significance of the t-statistics tells us that the model is good at explaining the variance in excess returns, one questions whether the model captures the fat tails in the distribution of PEAD returns and other non-linear phenomena. The regression residuals after sorting by the dependent variable, excess returns, indicate that the regression model fails to capture the non-linearity in the data at the extremes. A non-linear modelling technique should give better results, but such an exercise is beyond the scope of this paper.

\section{CONCLUSIONS}

The empirical evidence presented in this paper shows that unexpected earnings are a statistically significant 
predictor of returns subsequent to earnings announcements. The null hypothesis, that there is no relationship between unexpected earnings and the subsequent returns in the period following the announcement, is rejected. The post-earnings announcement drift anomaly, which can be regarded as an initial under-reaction to earnings news, occurred on the JSE for the period from 1991 to 2010; it is found to be statistically significant and to exist independently of the size, value and momentum effects.

These results are in contrast to the findings of Bhana (1995) who found that on the JSE for the period 1975 to 1989 the market overreacted to earnings announcements. Bhana found that firms announcing a negative change in EPS fared better than the market in the 12 month period subsequent to earnings announcements, but that those firms announcing a positive change in EPS did not perform significantly worse than the market.

The deviation of unexpected earnings based hedged returns from the linear relation between risk and return for the other explanatory variables may be a further indication of a risk factor that is not accounted for by the single factor CAPM. This inability of the single factor CAPM to incorporate all relevant risks may lead to excess returns being overestimated for smaller firms. It is however argued that the ability of IR to separate PEAD returns is significant despite a possibly uncaptured risk factor as the anomaly persists after accounting for the size, value and momentum effects. It therefore seems to represent a clear violation of market efficiency and may present an exploitable profit opportunity. The effect of transaction cost should however be incorporated to test whether superior riskadjusted returns are indeed achievable.

The two proxies of unexpected earnings used in this research ( $\triangle E P S$ and IR) are both found to be related to post-earnings announcement returns at statistically significant levels. The variable $\triangle E P S$ is however a less significant predictor of PEAD returns than IR, which is in contrast to the findings of Foster et al., (1984) who found that unexpected earnings as calculated by the market's reaction (a measure very similar to IR) are not related to post-earnings announcement returns, but that only the change in earnings ( $\triangle E P S)$ is related to the post-announcement returns.

The observed PEAD effect in this research provides evidence that is very difficult to reconcile with the delayed response explanation of Bernard and Thomas (1989) and Hou and Moskowitz (2005). We found that the market reacts very quickly to the announced earnings (as reflected by the IR variable) and on average it is not until about the $20^{\text {th }}$ to $40^{\text {th }}$ trading day after the announcement that the market starts drifting in the direction of the initial reaction. A possible explanation is that the market does not under-react to the earnings information at first, but that it receives confirmation in the two months following the announcement that is indicative of better future prospects and that the higher than expected earnings might persist. In retrospect, when only considering earnings news, it may therefore appear that the market under-reacted to the information released at the earnings announcement. The nature of such confirmation is however unclear, but it may be further information in the form of management forecasts or operational updates that is released into the market.

\section{REFERENCES}

Ball R and Brown P. 1968. An empirical evaluation of accounting income numbers. Journal of Accounting Research, 6(2):159-178.

Bernard VL and Thomas JK. 1989. Post-earningsannouncement drift: Delayed price response or risk premium? Journal of Accounting Research, 27:1-36.

Bhana N. 1995. The share market reaction to earnings announcements - a test of the efficiency of the Johannesburg Stock Exchange. Investment Analysts Journal, 42:45-57.

Bhana N. 1997. Price adjustments on the JSE for announcements of share (stock) dividends. Investment Analysts Journal, 46:35-44.

Bhana N. 1998. The share price reaction on the Johannesburg Stock Exchange for special (extra) dividend announcements. Investment Analysts Journal, 47:5-15.

Bhana N. 2005. The share price reaction to management buyout announcements of companies listed on the JSE Securities Exchange. Investment Analysts Journal, 62:19-30.

Bhana N. 2007. The market reaction to open market share repurchases announcements: The South African experience. Investment Analysts Journal, 65:25-36.

Bodie Z, Kane A and Marcus AJ. 2005. Investments (6th ed.). Singapore: McGraw-Hill Companies.

Brooks LR and Buckmaster D. 1980. First difference signals and accounting income time series properties. Journal of Business Finance \& Accounting, 7(3):437454.

Choi W and Kim JW. 2001. Underreaction, trading volume and post earnings announcement drift. Working Paper. [online] SSRN:

httpo://ssrn.com/abstract=2878217

Chordia T, Sadka R, Goyal A, Sadka G and Shivakumar L. 2007. Liquidity and the post-earningsannouncement drift. AFA 2008 New Orleans Meetings Paper. 
Chordia T and Shivakumar L. 2005. Inflation illusion and post-earnings-announcement drift. Journal of Accounting Research, 43(4):521-556.

De Bondt WFM and Thaler R. 1985. Does the stock market overreact? Journal of Finance, 40(3):793-805.

Foster G, Olsen C and Shevlin T. 1984. Earnings releases, anomalies, and the behavior of security returns. The Accounting Review, LIX(4):574-603.

Francis J, Lafond R, Olsson P, and Schipper K. 2007. Information uncertainty and post-earningsannouncement-drift. Journal of Business Finance \& Accounting, 34(3-4).

Hong $\mathrm{H}$ and Stein JC. 1999. A unified theory of underreaction, momentum trading and overreaction in asset markets. The Journal of Finance, LIV(6):21432184.

Hou K and Moskowitz TJ. 2005. Market frictions, price delay, and the cross-section of expected returns. Review of Financial Studies, 18(3):981-1020.

Jacobs BI and Levy KN. 1988. Disentangling equity return regularities: New insights and investment opportunities. Financial Analysts Journal, (MayJune):18-43.

Jensen MC. 1968. The performance of mutual funds in the period 1945-64. Journal of Finance, (May):389416.

Johnson RA and Wichern D. W. 2007. Applied multivariate statistical analysis (6th Ed.). Upper Saddle River: Prentice Hall.

Kaestner M. 2006. Investors' misreaction to unexpected earnings: Evidence of simultaneous overreaction and underreaction. ICFAI Journal of Behavioral Finance, 3(1):1-17.
Kaniel R, Shuming L, Saar G and Titman S. 2008. Individual investor trading and return patterns around earnings announcements. EFA 2009 Bergen Meetings Paper. Johnson School Research Paper No. 07-09.

Kim D and Kim M. 2003. A multifactor explanation of post-earnings announcement drift. Journal of Financial and Quantitative Analysis, 38(2):383-398.

Lundstrum L. 2010. Post-earnings announcement drift: Horserace of the theories. Retrieved July 27, 2011, from

http://69.175.2.130/ finman/Reno/Papers/PEADhorser ace011509.pdf

Marais ML. 1989. Discussion of post-earningsannouncement drift: Delayed price response or risk premium? Journal of Accounting Research, 27:37-48.

Mendenhall R. 2004. Arbitrage risk and post-earningsannouncement drift. Journal of Business, 77(4):875894.

$\mathrm{Ng} \mathrm{J,} \mathrm{Rusticus} \mathrm{TO,} \mathrm{and} \mathrm{Verdi} \mathrm{RS.} \mathrm{2008.} \mathrm{Implications} \mathrm{of}$ transaction costs for the post-earnings announcement drift. Journal of Accounting Research, 46(3):661-696.

Sadka R. 2006. Momentum and post-earningsannouncement drift anomalies: The role of liquidity risk. Journal of Financial Economics, 80(2):309-349.

Shanthikumar DM. 2004. Small and large trades around earnings announcements: Does trading behavior explain post-earnings-announcement drift? (September 2003). [online] SSRN: http://ssrn.com/abstract $=449800$

Shleifer A and Vishny RW. 1997. The Limits of Arbitrage. The Journal of Finance, 52(1):35-55. 


\section{Appendix A:}

\section{Definitions of Explanatory variables:}

All values are calculated at the last month-end before the earnings announcement.

- Earnings Yield (EY)

- $\quad$ Dividend Yield (DY)

$$
E Y=\frac{\text { Earnings per share }}{\text { Closing Price of share }} \times 100
$$

- Book-to-Market (B2M)

$$
D Y=\frac{\text { Dividend per share }}{\text { Closing Price of share }} \times 100
$$

$$
B 2 M=\frac{\text { Net Asset Value per share }}{\text { Closing Price of share }}
$$

The Net Asset Value (NAV) is calculated from the balance sheet according to the following formula:

$$
N A V=\text { Total Assets }- \text { Total Liabilities }
$$

- PreEAD - Cumulative returns for the ten day period just prior to the earnings announcement day $(t=0)$.

$$
\operatorname{PreEAD}, i=\sum_{t=-10}^{0} R_{i, t}
$$

- Absolute Momentum (Mom6) - The cumulative returns for the 6 month period before the last month-end prior to the announcement day.

$$
\text { Mom6 }_{, i}=\sum_{t=\text { MonthEnd }, i-120}^{\text {MonthEnd }, i} R_{i, t}
$$

- Market momentum (MS6) - The cumulative value weighted market returns for the 6 month period before the last month-end prior to the announcement day.

$$
M S 6_{, i}=\sum_{t=\text { MonthEnd,i-120 }}^{\text {MonthEnd, } i} R_{M, t}
$$

- Relative Momentum (RS6) - The cumulative returns for the 6 month period before the last month-end prior to the announcement day relative to the cumulative market return for the same period.

The above equation can also be written as:

$$
R S 6_{, i}=\sum_{t=\text { MonthEnd,i-120 }}^{\text {MonthEnd,i }}\left(R_{i, t}-R_{M, t}\right)
$$

$$
R S 6_{, i}=M{ }^{2} 6_{, i}-M S 6_{, i}
$$

- Share turnover (ST3) - Average daily volume of shares traded for the three months prior to the earnings announcement as a fraction of the total number of issued shares.

$$
S T 3=\frac{1}{60} \sum_{t=\text { MonthEnd }, i-60}^{\text {MonthEnd, } i} \text { Volume }_{t, i} / \text { Number of shares issued }
$$

- Market Capitalisation (MC)

$$
\text { Market Capitalisation }=\text { Closing Price } \times \text { Number of shares issued }
$$

